\title{
DISTRIBUIÇÃO DE RAÍZES DE BANANEIRA 'PRATA-ANÃ' NO SEGUNDO CICLO DE PRODUÇÃO SOB TRÊS SISTEMAS DE IRRIGAÇÃ ${ }^{1}$
}

\author{
JOSÉ ANTONIO DO VALE SANT'ANA ${ }^{2}$, EUGÊNIO FERREIRA COELHO ${ }^{3}$, \\ MANOEL ALVES DE FARIA ${ }^{4}$, ELIO LEMOS DA SILVA 5 , SÉRGIO LUIZ RODRIGUES DONATO 6
}

RESUMO- A informação da distribuição radicular de uma planta permite definir áreas do solo ao redor desta, mais propícia para aplicação de fertilizantes e instalação de sensores de umidade, para melhor monitoramento da irrigação. O presente trabalho teve como objetivo avaliar a distribuição do sistema radicular de bananeira 'Prata-Anã', sob diferentes sistemas de irrigação, durante o segundo ciclo de produção. O delineamento experimental foi em blocos casualizados, com parcelas subdivididas, com três repetições, em que as fontes de variação se constituíram de três sistemas de irrigação (gotejamento, microaspersão e aspersão convencional), seis distâncias da planta $(0,15 ; 0,30 ; 0,45 ; 0,60 ; 0,75$ e $1,00 \mathrm{~m})$ e cinco camadas do solo $(0,0-0,20$; $0,20-0,40 ; 0,40-0,60 ; 0,60-0,80$ e $0,80-1,00 \mathrm{~m})$. A bananeira apresentou maior predominância do sistema radicular próxima à superfície do solo, com $80 \%$ deste a $0,61 \mathrm{~m}, 0,51 \mathrm{~m}$ e $0,61 \mathrm{~m}$ e à distância efetiva de 0,63 $\mathrm{m}, 0,66 \mathrm{~m}$ e $0,79 \mathrm{~m}$ do pseudocaule da planta, para os sistemas de irrigação por gotejamento, microaspersão e aspersão convencional, respectivamente. Em geral, predominaram as raízes com diâmetros inferiores a 2 $\mathrm{mm}$, em toda a zona radicular avaliada. As raízes com maior diâmetro tenderam a concentrar-se próximo ao pseudocaule da planta com profundidades inferiores a $0,40 \mathrm{~m}$ da superfície do solo.

Termos para indexação: imagens digitais, sistema radicular, Musa spp.

\section{ROOT DISTRIBUTION OF 'PRATA-ANÃ' BANANA IN THE SECOND PRODUCTION CYCLE UNDER THREE IRRIGATION SYSTEMS}

\begin{abstract}
The information of a plant root distribution allows defining regions of soil around it suitable for fertilizer application and for sensor placement in order to improve irrigation schedule. The present study had as objective to evaluate root system distribution of banana cv.'Prata-Anã' irrigated by different systems, during the second production cycle. The experiment followed a random block design in a split split-plot scheme with three replications in which the variation sources consisted of three irrigation systems (drip, microsprinkler and conventional sprinkler), six distances from plant $(0.15 ; 0.30 ; 0.45 ; 0.60 ; 0.75 \mathrm{e}$ $1.00 \mathrm{~m})$ and five soil depths $(0.0-0.20 ; 0.20-0.40 ; 0.40-0.60 ; 0.60-0.80$ and $0.80-1.00 \mathrm{~m})$. The banana root system remained near-surface soil, with its $80 \%$ at $0.61 \mathrm{~m}, 0.51 \mathrm{~m}$ and $0.61 \mathrm{~m}$ depth and at effective distance of $0.63 \mathrm{~m}, 0.66 \mathrm{~m} 0.79 \mathrm{~m}$ from the pseudostem for irrigation systems, drip micro sprinkler and conventional sprinkler, respectively. In general there were more roots with diameter less than $2 \mathrm{~mm}$ all over the evaluated root zone. The roots of larger diameter tended to concentrate near to the pseudostem with depths less than $0.40 \mathrm{~m}$ from soil surface.
\end{abstract}

Index terms: digital image, root system, Musa spp.

\footnotetext{
${ }^{1}$ (Trabalho 177-11). Recebido em: 06-06-2011. Aceito para publicação em: 05-12-2011. Parte da dissertação de mestrado em Recursos Hídricos em sistemas Agrícolas, UFLA/MG, do primeiro autor.

${ }^{2}$ Doutorando do PPG Recursos Hídricos em Sistemas Agrícolas, Bolsista CAPES (DEG/UFLA). E-mail: jantonio@posgrad.ufla.br ${ }^{3}$ Pesquisador da EMBRAPA/CNPMF. CEP: 44380-000. Cruz das Almas-BA. E-mail: eugenio@cnpmf.embrapa.br

${ }^{4}$ Professor da Universidade Federal de Lavras. CEP: 37200-000. Lavras-MG. E-mail: mafaria@ufla.br ${ }^{5}$ Professor da Universidade Federal de Lavras. CEP: 37200-000. Lavras-MG. E-mail: elemos@deg.ufla.br

${ }^{6}$ Professor do IFBaiano, Câmpus Guanambi-BA. CEP 46430-000. E-mail: sergiodonatoeaf@yahoo.com.br
} 


\section{INTRODUÇÃO}

O Brasil é o quarto maior produtor de banana do mundo, sendo esta uma das frutas mais consumidas no País (FOOD AND AGRICULTURA ORGANIZATION OF THE UNITED NATIONS - FAO, 2010). A região Nordeste destaca-se como responsável pela maior produção, com 2,99 milhões de toneladas, ocupando uma área de 241.467 ha, correspondente a $40,6 \%$ da produção total do País, seguida pelo Sudeste, com $30,4 \%$ da produção. Apesar da maior produção, a produtividade média da região Nordeste, $12,36 \mathrm{t} \mathrm{ha}^{-1}$, é baixa, enquanto as regiões Sudeste e Sul apresentam rendimentos médios de 16,05 tha- $\mathrm{e}^{-1}$, $08 \mathrm{t} \mathrm{ha}^{-1}$, respectivamente (IBGE, 2010).

No Brasil, a banana constitui parte da alimentação das diversas camadas sociais, como sobremesa e também como fonte alimentar (CAMPOS et al., 2003), além de assumir um importante papel na fixação da mão de obra rural.

Cultivos de bananeira sob diferentes sistemas de irrigação podem diferir quanto à produtividade, ainda que se utilizem das mesmas cultivares e condições de cultivo. Isto decorre de diferenças na aplicação da água relacionadas à uniformidade de distribuição, à área e ao volume molhados, à intensidade e frequência de aplicação, o que pode alterar a distribuição espacial do sistema radicular, os atributos químicos do solo e o fluxo convectivodispersivo de nutrientes e, portanto, afetar os teores de nutrientes na planta (DONATO et al., 2010).

No perfil do solo, nutrientes e água não são igualmente distribuídos. O desenvolvimento do sistema radicular é determinado pelas características das espécies e fatores ambientais, tais como o clima e as características físicas, químicas e biológicas do solo (LEHMANN, 2003).

Em relação à irrigação, informações sobre a distância e a profundidade efetiva das raízes são importantes, uma vez que uma estimativa errada da profundidade do sistema radicular pode levar a déficit ou a excesso do valor da lâmina de irrigação. De acordo com Coelho et al. (2002), para a irrigação localizada ou microirrigação, tal como a microaspersão, apenas o conhecimento da profundidade efetiva do sistema radicular não é suficiente para inferir sobre as zonas de absorção de água e nutrientes, uma vez que a geometria de distribuição de água é de caráter multidirecional e difere do caráter unidirecional da irrigação por aspersão.

Segundo Ruiz-Sanchez et al. (2005), na irrigação de áreas áridas e semiáridas por gotejamento, ocorrem significativas concentrações de raízes na zona molhada. Neilsen et al. (2000) compararam a distribuição das raízes em macieiras com sete anos, utilizando dois sistemas de irrigação, e observaram que as árvores sob irrigação por aspersão se caracterizaram por sistema radicular superficial e apresentaram distribuição mais uniforme que as árvores sob irrigação por gotejamento. Carr (2009) relata que, embora as raízes possam estender-se até a profundidades de 1,0-1,5 m, a profundidade "eficaz" de enraizamento normalmente se localiza entre 0,0 $0,40 \mathrm{~m}$, às vezes estendendo-se até $0,60 \mathrm{~m}$. Bassoi et al. (2004) pesquisaram a distribuição e a atividade radicular da bananeira 'Pacovan' (AAB) sob irrigação por microaspersão em um solo de textura média e com plantas espaçadas em $3 \times 3 \mathrm{~m}$. Verificaram que a profundidade efetiva das raízes foi de $0,4 \mathrm{~m}$ até os 91 dias após o plantio (dap), aumentando para 0,6 m aos 370; 510 e 903 dap. Lacerda Filho et al. (2004) avaliaram a densidade do sistema radicular da bananeira 'Pacovan' sob irrigação por aspersão e constataram redução na densidade do comprimento de raízes em função da profundidade do solo.

Informação sobre a distribuição radicular de uma planta permite definir áreas do solo ao seu redor mais propícias para aplicação de fertilizantes e para instalação de sensores do estado de água no solo (umidade e potencial matricial) para melhor manejo da irrigação. O presente trabalho teve como objetivo avaliar a distribuição do sistema radicular de bananeira 'Prata-Anã', sob diferentes sistemas de irrigação, durante o segundo ciclo de produção, em condições do semiárido do sudoeste da Bahia.

\section{MATERIAL E MÉTODOS}

O presente estudo foi conduzido no campo experimental do Instituto Federal de Educação, Ciência e Tecnologia Baiano, Câmpus Guanambi, Município de Guanambi (14¹3'30”'S; 4246'53”W; $525 \mathrm{~m}$ de altitude), região sudoeste da Bahia. O clima é considerado semiárido, com precipitação média anual de $664 \mathrm{~mm}$, temperatura média anual de $26^{\circ} \mathrm{C}$ e umidade relativa média anual do ar de $64 \%$. O solo da área é um Latossolo Vermelho-Amarelo distrófico típico, textura média, fase caatinga hipoxerófila, relevo plano a suave ondulado (DONATO et al., 2010; EMBRAPA, 2006).

As características físico-hídricas do solo encontram-se na Tabela 1. A frutífera estudada foi a bananeira (Musa spp.), cultivar Prata-Anã, plantada em fileiras simples, no espaçamento de 3,0 x 2,5 m. As mudas micropropagadas foram cedidas pela Embrapa Mandioca e Fruticultura Tropical. A implantação e os tratos culturais seguiram as recomendações 
para a cultura, conforme Rodrigues et al. (2008).

$\mathrm{O}$ experimento foi instalado no delineamento experimental em blocos casualizados em esquema de parcelas subdivididas, com três repetições. As parcelas constituíram-se de três sistemas de irrigação (gotejamento, microaspersão e aspersão convencional), as subparcelas consistiram em seis distâncias da planta $(0,15 ; 0,30 ; 0,45 ; 0,60 ; 0,75$ e $1,00 \mathrm{~m})$ e as subsubparcelas de cinco camadas do solo $(0,0$ $-0,20 ; 0,20-0,40 ; 0,40-0,60 ; 0,60-0,80$ e 0,80 $1,00 \mathrm{~m}$ de profundidade). No bananal, foram adotadas as práticas rotineiras de um pomar comercial e irrigações feitas com base na evapotranspiração da cultura (ETc), calculada conforme Doorembos e Kassam (1994).

As amostragens das raízes foram feitas em três plantas de porte similar, para cada sistema de irrigação, durante a fase de produção do segundo ciclo. A coleta das amostras de raízes no campo foi realizada com uso de uma variação do método do trado, conforme Coelho et al. (2008). As amostras foram retiradas em seis distâncias da planta $(0,15$; 0,$30 ; 0,45 ; 0,60 ; 0,75$ e $1 \mathrm{~m}$ ) até a profundidade de 1 $\mathrm{m}$, sendo as posições de amostragem definidas pela região de maior umidade, para efeito de comparação entre os sistemas. No caso do sistema de gotejamento, foram tomadas a partir do pseudocaule da planta, na direção da fileira de plantas, seguindo a linha do gotejo. No sistema de microaspersão, as amostragens foram realizadas a partir do pseudocaule da planta em direção ao microaspersor. A coleta da aspersão convencional foi feita na direção longitudinal e ortogonal à fileira de plantas. As raízes foram separadas do solo por lavagem (BÖHM, 1979), em seguida digitalizadas, conforme Coelho et al. (2005). Os dados de comprimento de raízes permitiram a determinação da densidade de comprimento de raízes (DCR) em $\mathrm{cm} \mathrm{cm}^{-3}$, pela razão entre o comprimento de todos os segmentos de raízes da amostra (Lr) em cm e o volume da amostra (Vr) em $\mathrm{cm}^{3}$. Foram feitas análises de distribuição das raízes em um plano bidimensional, para os três sistemas de irrigação, de forma a gerar gráficos de distribuição de percentagem de raízes totais nas distâncias e profundidades avaliadas. Consideraram-se como profundidade e distância efetiva as regiões onde se concentraram $80 \%$ do comprimento total de raízes, conforme sugeriram Kanber et al. (1996) e Vieira et al. (1996). Procedeu-se à análise de variância dos dados para verificar a diferença entre a densidade de comprimento de raízes nos sistemas e comparou-se o diâmetro relativo de raízes em diferentes classes, conforme a Tabela 2 (BÖHM, 1979).

\section{RESULTADOS E DISCUSSÃO}

Houve interação significativa entre os sistemas de irrigação e a distância do pseudocaule da bananeira para a variável DCR (Tabela 3). No sistema por gotejamento, a DCR foi maior para as distâncias do pseudocaule de 0,15 e $0,30 \mathrm{~m}$, comparada às maiores distâncias avaliadas $(0,60 \mathrm{~m}, 0,75$ m e 1,0 m). Na microaspersão, a DCR foi maior a $0,15 \mathrm{~m}$ do pseudocaule. Na aspersão convencional, a DCR foi similar em todas as distâncias do pseudocaule (Tabela 3). Nas distâncias de 0,15 e 0,45 m do pseudocaule, o sistema por gotejamento apresentou maior DCR, comparado ao sistema de irrigação por aspersão convencional. A $0,30 \mathrm{~m}$, a DCR foi maior no sistema de irrigação por gotejamento, comparado aos sistemas de irrigação por microaspersão e aspersão convencional (Tabela 3 ).

Os dados apresentaram alta variabilidade (CV entre 25,73 e 64,91\%) (Tabelas 3 e 4). Tal fato ocorreu devido à variação intrínseca do solo, associada à grande variação da densidade radicular entre as camadas do solo, além da variabilidade da distância do pseudocaule da planta. Segundo Ramos et al. (2009), coeficientes de variação (CV) elevados são correntemente detectados em trabalhos envolvendo análise do sistema radicular. Esses autores, ao estudarem a distribuição espacial do sistema radicular da pupunheira em função de lâminas de irrigação, encontraram CV entre $23,62 \%$ e $225,68 \%$. Selle et al. (2010) avaliaram a biomassa de raízes finas em um povoamento de Pinus sp. em Santa Maria (RS) e verificaram valor elevado de coeficiente de variação $(\mathrm{CV}=85,33 \%)$. Oliveira (2008) também encontrou altos valores de CV (entre $24,34 \%$ e $58,22 \%$ ) ao pesquisar a influência de doses de fósforo em arranjos populacionais variáveis sobre o desenvolvimento radicular da palma forrageira.

A variável DCR foi influenciada pelas camadas do solo, independentemente dos sistemas de irrigação. As camadas do solo próximo à superfície $(0-0,2 \mathrm{~m}$ e $0,2-0,4 \mathrm{~m})$ diferiram das mais profundas. A camada de $0,4-0,6 \mathrm{~m}$ apresentou maior valor que a camada de $0,8-1,0 \mathrm{~m}$ (Tabela 4 ).

Os sistemas de irrigação por gotejamento e aspersão convencional apresentaram valores iguais para profundidade efetiva do sistema radicular da bananeira, com $80 \%$ detectados a $0,61 \mathrm{~m}$ da superfície do solo, enquanto no sistema de irrigação por microaspersão a profundidade efetiva foi a $0,51 \mathrm{~m}$ (Figura 1). Este resultado está de acordo com Bassoi et al. (2004) que, estudando a distribuição e a atividade radicular da bananeira 'Pacovan' (AAB) sob irrigação por microaspersão, constataram que a 
profundidade efetiva das raízes foi de $0,4 \mathrm{~m}$ até os 91 dias após o plantio (DAP), aumentando para 0,6 $\mathrm{m}$ aos 370; 510 e 903 DAP. Santos et al. (2006), estudando a distribuição do sistema radicular da bananeira sob diferentes configurações do sistema de irrigação por aspersão, detectaram que a profundidade onde estão pelo menos $80 \%$ do total acumulado das raízes é de $0,50 \mathrm{~m}$ da superfície do solo. $\mathrm{Na}$ Figura 2, verifica-se que a distância efetiva ficou a $0,63 \mathrm{~m}$ do pseudocaule da planta para o sistema de irrigação por gotejamento, $0,66 \mathrm{~m}$ para o sistema de irrigação por microaspersão e a $0,79 \mathrm{~m}$ para o sistema de irrigação por aspersão convencional.

Os valores de DCR no perfil do solo estudado mostram que, em relação às profundidades e à distância do pseudocaule, os três sistemas de irrigação apresentaram comportamentos diferentes (Figuras 3a, 3b e 3c).

$\mathrm{O}$ sistema por gotejamento apresentou maior concentração radicular nos primeiros $0,20 \mathrm{~m}$ de profundidade até $0,4 \mathrm{~m}$ de distância da planta. Entretanto, esse sistema apresentou valores de DCR mais altos que a microspersão e aspersão convencional, nas profundidades inferiores a $0,20 \mathrm{~m}$ (Figura $3 \mathrm{a}$ ). $\mathrm{O}$ maior valor de DCR foi de $2,12 \mathrm{~cm} \mathrm{~cm}^{-3}$. Esse resultado corrobora Coelho et al. (2008) que encontraram valores de densidade máxima de comprimento entre $1,6 \mathrm{~cm} \mathrm{~cm}^{-3}$ e $2,2 \mathrm{~cm} \mathrm{~cm}^{-3}$.

O sistema de irrigação por microaspersão apresentou alta concentração do sistema radicular entre 0,0 - 0,50 $\mathrm{m}$ de profundidade, estendendo-se até $0,60 \mathrm{~m}$ de distância da planta (Figura 3b). O sistema por aspersão convencional foi o que apresentou os menores valores de DCR, com alta atividade do sistema radicular localizado entre $0,0-0,50 \mathrm{~m}$, ao longo de todo o perfil avaliado (Figura 3c). No sistema por aspersão convencional, não foi detectado valor de DCR acima de $1,1 \mathrm{~cm} \mathrm{~cm}^{-3}$. Tais resultados podem ser justificados pelo fato de esse sistema de irrigação distribuir a água numa área maior, possibilitando, assim, maior uniformização da umidade do solo na superfície, enquanto o sistema por gotejamento, por apresentar aplicação de água pontual, limita essa uniformização, permitindo regiões com maiores concentrações radiculares. Isso está de acordo com os resultados de Neilsen et al. (2000), que verificaram significativas concentrações de raízes abaixo do gotejador, à profundidade de $0,4 \mathrm{~m}$.

A Figura 4 ilustra a distribuição das percentagens de comprimento total de raízes de diferentes diâmetros para as diferentes profundidades e distâncias do pseudocaule da planta. Observa-se que, no sistema por gotejamento, há predomínio de raízes muito finas $(<0,5 \mathrm{~mm})$ para as profundidades me- nores que $0,60 \mathrm{~m}$ e distância da planta inferior a 0,80 $\mathrm{m}$. As raízes pequenas $(0,5-2,0 \mathrm{~mm})$ tiveram maior abrangência no perfil para as distâncias superiores a $0,40 \mathrm{~m}$ e profundidade de $0,0-0,80 \mathrm{~m}$. As raízes com diâmetro de 2,0 a 5,0 mm tenderam a se concentrar a distâncias próximas da planta e nas profundidades $0,0-0,50 \mathrm{~m}$, com pequena presença para as profundidades acima de $0,50 \mathrm{~m}$ (Figura 4 ).

No sistema de irrigação por microaspersão, as raízes muito finas $(<0,5 \mathrm{~mm})$ apresentaram certa uniformidade no perfil do solo. Entretanto, as maiores percentagens ocorreram para profundidades de 0,0 a $0,6 \mathrm{~m}$ e para distâncias horizontais de até $1 \mathrm{~m}$. As raízes finas $(0,5-2,0 \mathrm{~mm})$ ocorreram com maior incidência até a profundidade de $0,4 \mathrm{~m}$ para distâncias horizontais de até $1,0 \mathrm{~m}$. As raízes pequenas $(2,0-5,0$ $\mathrm{mm}$ ) apresentaram maiores valores para as profundidades próximas à superfície do solo e distâncias horizontais inferiores a $0,4 \mathrm{~m}$ (Figura 5).

No sistema de irrigação por aspersão convencional, as raízes muito finas $(<0,5 \mathrm{~mm})$ ocuparam todo o perfil limitado pela profundidade de $0,60 \mathrm{~m}$. De modo geral, as raízes de maior diâmetro tenderam a se concentrar a menores distâncias do pseudocaule da planta e em profundidades inferiores a $0,40 \mathrm{~m}$ da superfície do solo (Figura 6).

Lecompte et al. (2005) verificaram variação entre 0,09 e 0,52 $\mathrm{mm}$ para raízes secundárias e entre 0,06 e $0,27 \mathrm{~mm}$ para as raízes terciárias. Borges et al. (2008), estudando a distribuição do sistema radicular da bananeira 'Prata-Anã' em duas frequências de fertirrigação com ureia, observaram predominância de raízes para as classes de diâmetro acima de 0,2 $\mathrm{mm}$, nas camadas superficiais entre a planta e o microaspersor. 
TABELA 1- Características físico-hídricas do solo da área experimental.

\begin{tabular}{c|c|c|c}
\hline \multicolumn{2}{c}{ Camadas do solo $(\mathrm{m})$} \\
\cline { 2 - 4 } Características & $0-0,20$ & $0,21-0,41$ & $0,40-0,60$ \\
\hline Areia $\left(\mathrm{g} \mathrm{kg}^{-1}\right)$ & 675,0 & 662,5 & - \\
Silte $\left(\mathrm{g} \mathrm{kg}^{-1}\right)$ & 75,0 & 88,3 & - \\
Argila $\left(\mathrm{g} \mathrm{kg}^{-1}\right)$ & 250,0 & 249,2 & - \\
Densidade do solo $\left(\mathrm{Mg} \mathrm{m}^{-3}\right)$ & 1,66 & 1,75 & 0,2325 \\
Retenção de água $-10 \mathrm{kPa}\left(\mathrm{m}^{3} \mathrm{~m}^{-3}\right)$ & 0,2102 & 0,2308 & 0,1125 \\
Retenção de água -1500 $\mathrm{kPa}\left(\mathrm{m}^{3} \mathrm{~m}^{-3}\right)$ & 0,1340 & 0,1325 & \\
\hline
\end{tabular}

TABELA 2 - Classificação das raízes quanto ao diâmetro.

\begin{tabular}{ccccccc}
\hline Classe & Muito fina & Fina & Pequena & Média & Grande & Muito grande \\
\hline Diâmetro $(\mathrm{mm})$ & $<0,5$ & $0,5-2,0$ & $2,10-5,0$ & $5,10-10,0$ & $10,0-20,0$ & $>20,0$ \\
\hline
\end{tabular}

TABELA 3 -Médias da densidade de comprimento $\left(\mathrm{cm} \mathrm{cm}^{-3}\right)$ de raízes, em função da distância do pseudocaule, no segundo ciclo da bananeira 'Prata-Anã', sob diferentes sistemas de irrigação, em Latossolo Vermelho - Amarelo distrófico.

\begin{tabular}{cccc}
\hline \multicolumn{4}{c}{ Sistemas de irrigação } \\
\hline Distância $(\mathrm{m})$ & Gotejamento & Microaspersão & Aspersão \\
\hline 0,15 & $2,12 \mathrm{~A} \mathrm{a}$ & $1,32 \mathrm{~A} \mathrm{ab}$ & $0,99 \mathrm{~A} \mathrm{~b}$ \\
0,30 & $2,04 \mathrm{~A} \mathrm{a}$ & $1,06 \mathrm{AB} \mathrm{b}$ & $0,86 \mathrm{~A} \mathrm{~b}$ \\
0,45 & $1,28 \mathrm{AB} \mathrm{a}$ & $0,89 \mathrm{AB} \mathrm{ab}$ & $0,47 \mathrm{~A} \mathrm{~b}$ \\
0,60 & $0,26 \mathrm{~B}$ a & $0,80 \mathrm{AB} \mathrm{a}$ & $0,35 \mathrm{~A} \mathrm{a}$ \\
0,75 & $0,29 \mathrm{~B} \mathrm{a}$ & $0,18 \mathrm{~B} \mathrm{a}$ & $0,23 \mathrm{~A} \mathrm{a}$ \\
1,00 & $0,24 \mathrm{~B}$ a & $0,07 \mathrm{~B} \mathrm{a}$ & $0,19 \mathrm{~A} \mathrm{a}$ \\
\hline $\mathrm{CV}(\%)=64,91$ &
\end{tabular}

Médias seguidas por letras maiúsculas iguais em coluna e minúsculas nas linhas não diferem entre si, pelo teste de Tukey, a 5\% de probabilidade.

TABELA 4- Médias da densidade de comprimento $\left(\mathrm{cm} \mathrm{cm}^{-3}\right)$ de raízes, em função das camadas do solo, na fase final do segundo ciclo da bananeira 'Prata-Anã', sob diferentes sistemas de irrigação, em Latossolo Vermelho - Amarelo distrófico.

\begin{tabular}{c|c|c|c}
\hline $\begin{array}{c}\text { Camadas do solo } \\
(\mathrm{m})\end{array}$ & $\begin{array}{c}\text { Densidade de } \\
\text { Comprimento }\left(\mathrm{cm} \mathrm{cm}^{3}\right)\end{array}$ & $\begin{array}{c}\text { Sistemas de irrigação } \\
\text { Densidade de Comprimento } \\
\left(\mathrm{cm} \mathrm{cm}^{3}\right)\end{array}$ \\
\hline $0-0,20$ & $1,06 \mathrm{a}$ & Gotejamento & $0,72 \mathrm{a}$ \\
$0,21-0,40$ & $0,88 \mathrm{a}$ & Microaspersão & $0,60 \mathrm{a}$ \\
$0,41-0,60$ & $0,55 \mathrm{~b}$ & Asp.Convencional & $0,57 \mathrm{a}$ \\
$0,61-0,80$ & $0,41 \mathrm{bc}$ & & \\
$0,81-1,00$ & $0,21 \mathrm{c}$ & & \\
\hline $\mathrm{CV}(\%)$ & 25,73 & & 46,67 \\
\hline
\end{tabular}

Médias seguidas por letras iguais na coluna não diferem entre si, pelo teste de Tukey, a 5\% de probabilidade. 


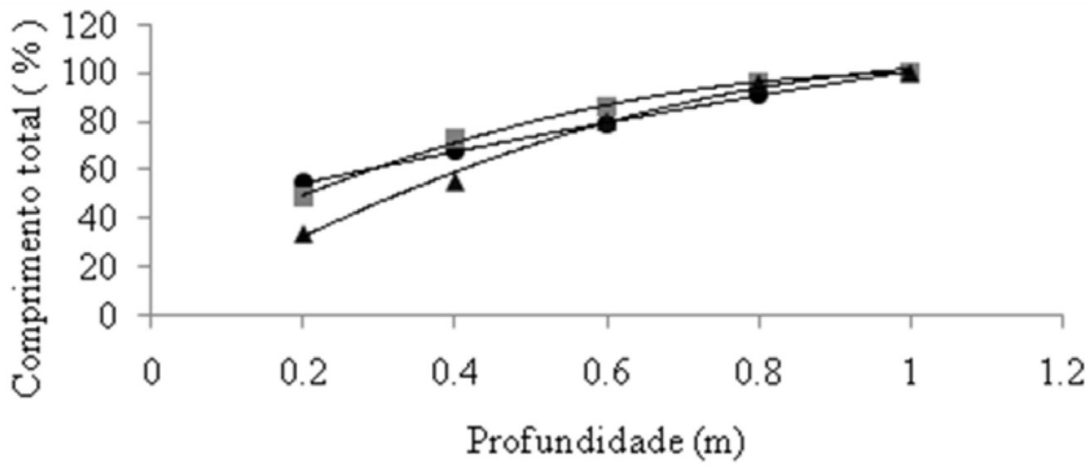

- S1; $\mathrm{Y}=-11.81 \mathrm{X}^{2}+71.17 \mathrm{X}+40.92 \mathrm{R}^{2}=0.999$

$\mathrm{S} 2 ; \mathrm{Y}=-76.76 \mathrm{X}^{2}+155.2 \mathrm{X}+21.04 \mathrm{R}^{2}=0.997$

^S3; $\mathrm{Y}=-78.20 \mathrm{X}^{2}+180.2 \mathrm{X}-0.752 \mathrm{R}^{2}=0.992$

FIGURA 1- Percentagem de comprimento total das raízes em função da profundidade do solo, na fase final do segundo ciclo da bananeira 'Prata-Anã', sob sistema de irrigação por gotejamento (S1), microaspersão (S2) e aspersão convencional (S3), em Latossolo Vermelho -Amarelo distrófico.

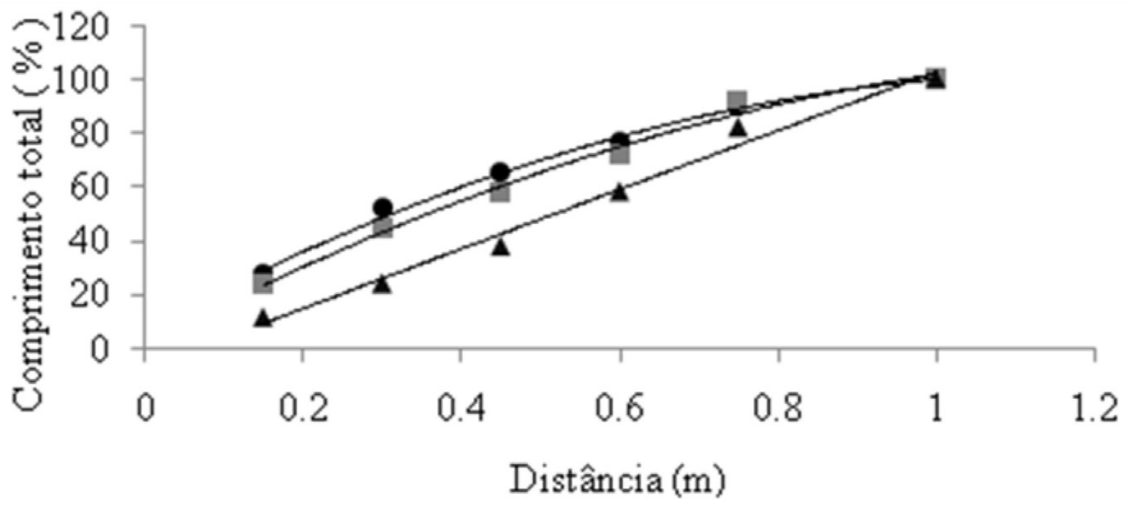

- S1; $\mathrm{Y}=-66.00 \mathrm{X}^{2}+158.7 \mathrm{X}+6.970 \mathrm{R}^{2}=0.994$

$\mathrm{S} 2 ; \mathrm{Y}=-54.77 \mathrm{X}^{2}+154.2 \mathrm{X}+1.972 \quad \mathrm{R}^{2}=0.997$

A $\mathrm{S} 3 ; \mathrm{Y}=-1.522 \mathrm{X}^{2}+111.9 \mathrm{X}-7.84 \quad \mathrm{R}^{2}=0.992$

FIGURA 2 - Percentagem de comprimento total das raízes em função da distância do pseudocaule, na fase final do segundo ciclo da bananeira 'Prata-Anã', sob sistema de irrigação por gotejamento (S1), microaspersão (S2) e aspersão convencional (S3), em Latossolo Vermelho-Amarelo distrófico. 

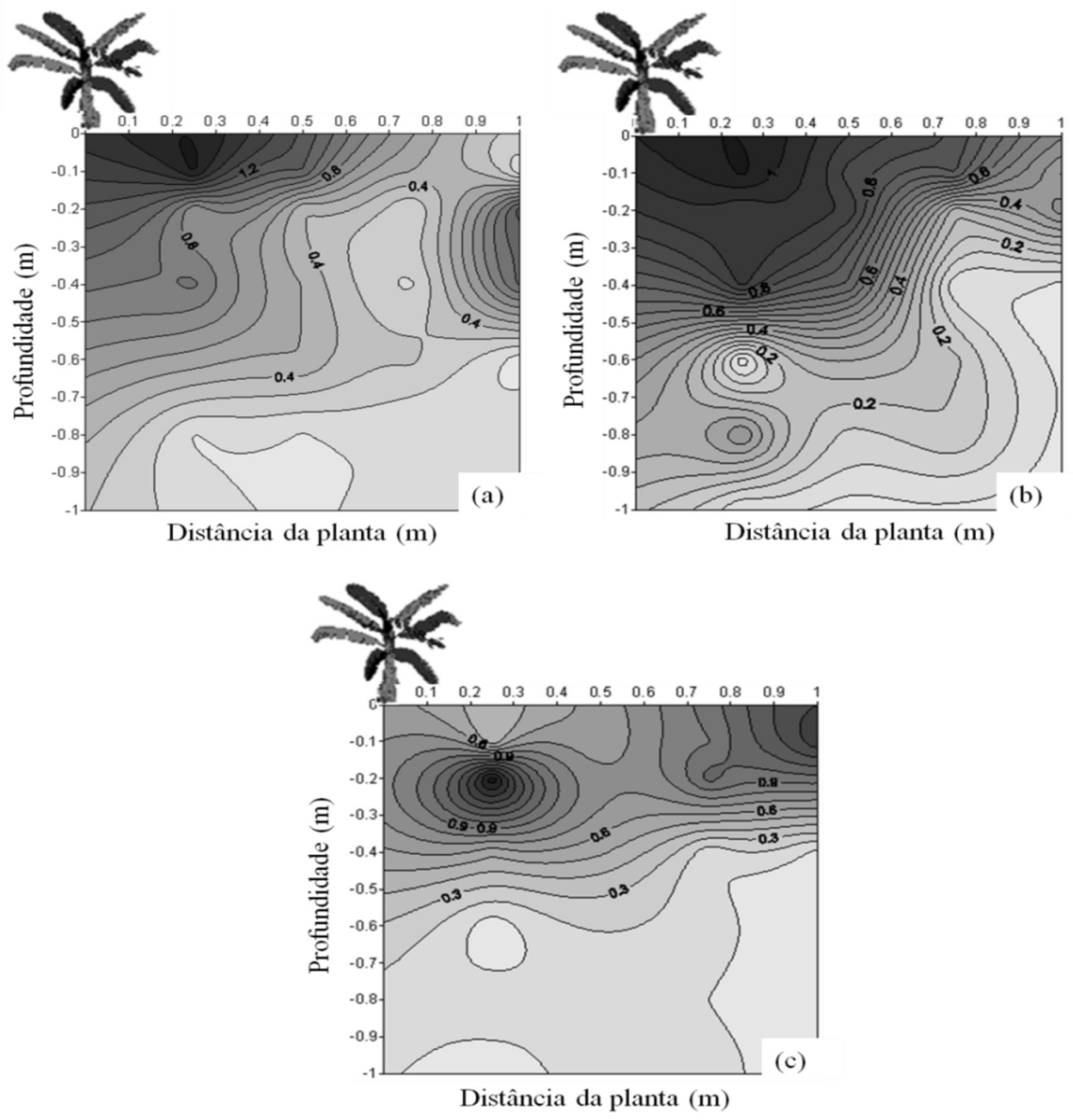

FIGURA 3- Isolinhas de densidade de comprimento de raízes no perfil do solo para os sistemas por gotejamento (a), microaspersão (b) e aspersão convencional (c), na fase final do segundo ciclo da bananeira 'Prata-Anã', no Latossolo Vermelho-Amarelo distrófico. 


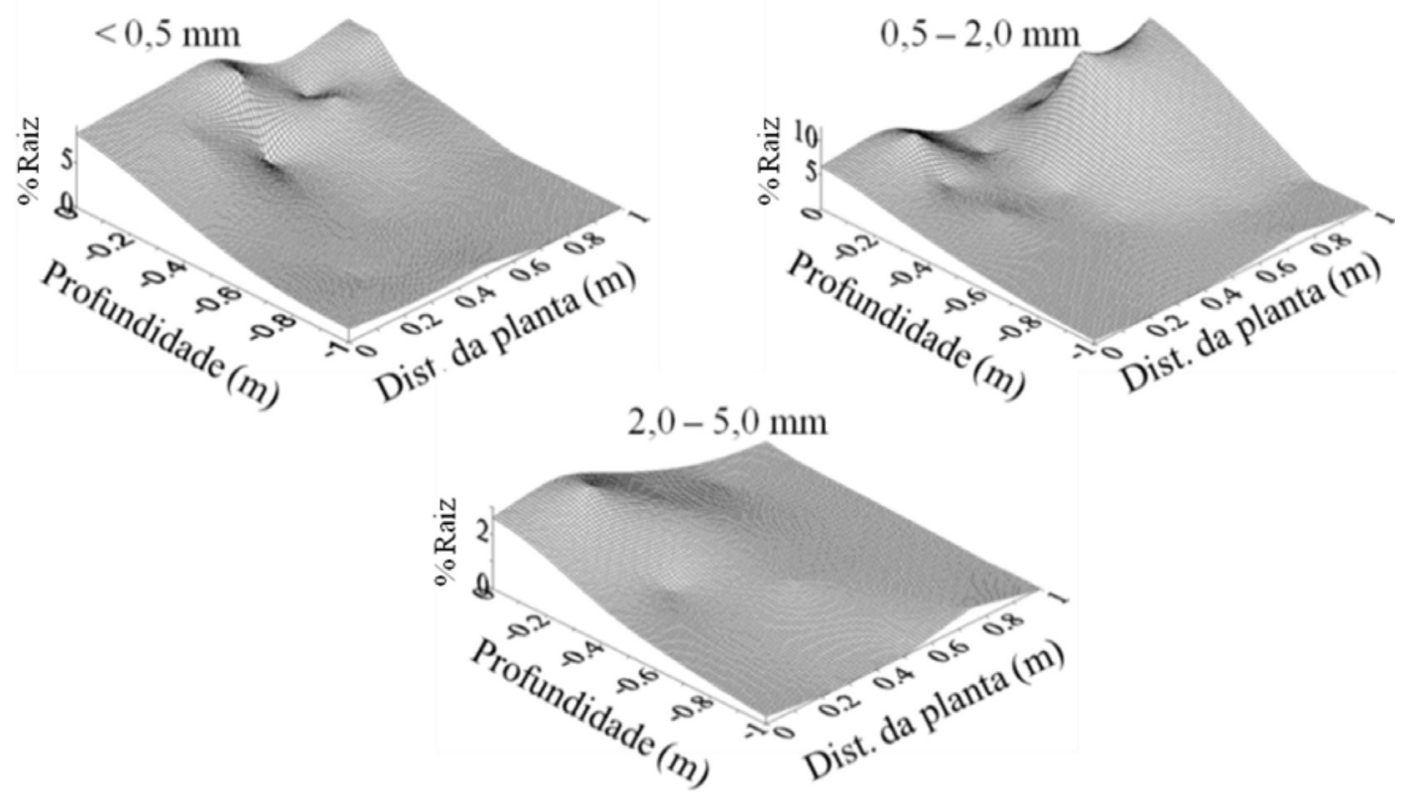

FIGURA 4 - Percentagens de comprimento de raízes de diferentes diâmetros relativo ao comprimento total de raízes de bananeira 'Prata-Anã' sob irrigação por gotejamento, tendo a planta na posição zero.
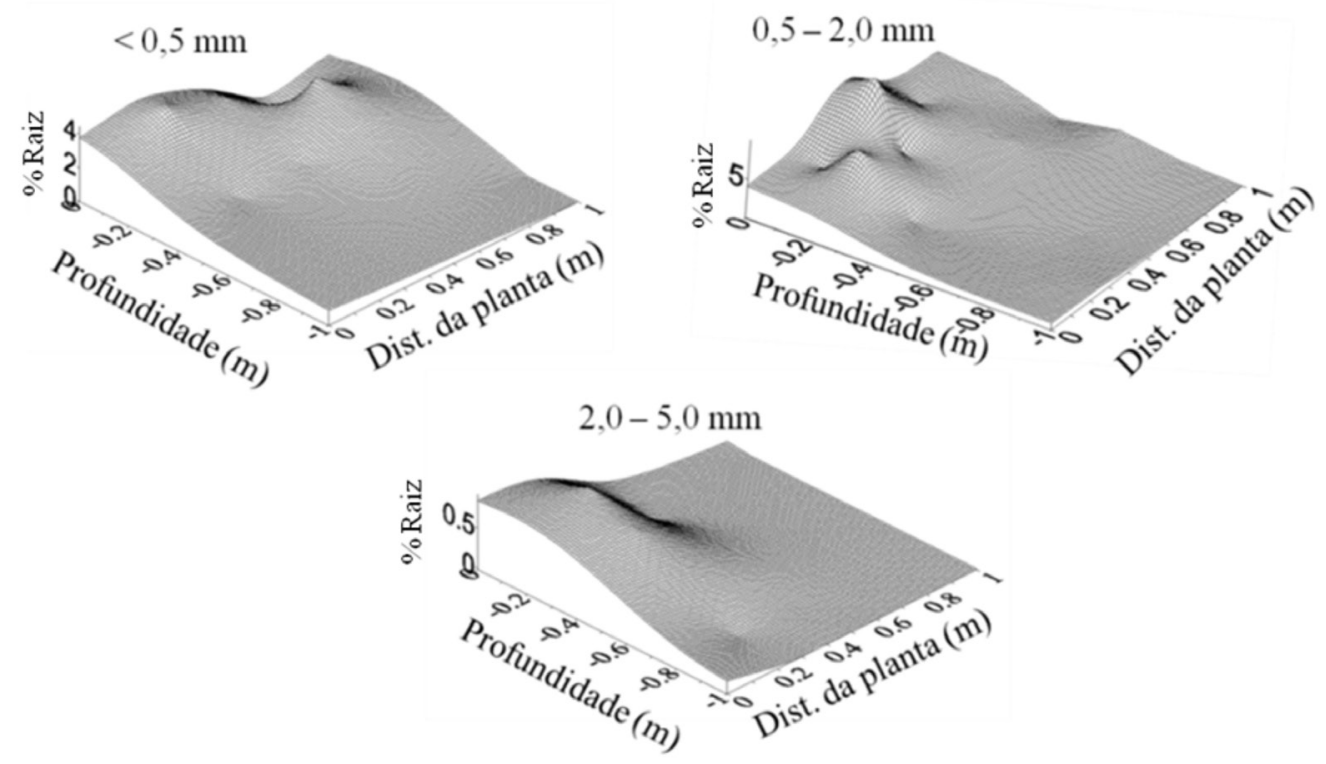

FIGURA 5 - Percentagens de comprimento de raízes de diferentes diâmetros relativo ao comprimento total de raízes de bananeira 'Prata-Anã' sob irrigação por microaspersão, tendo a planta na posição zero. 

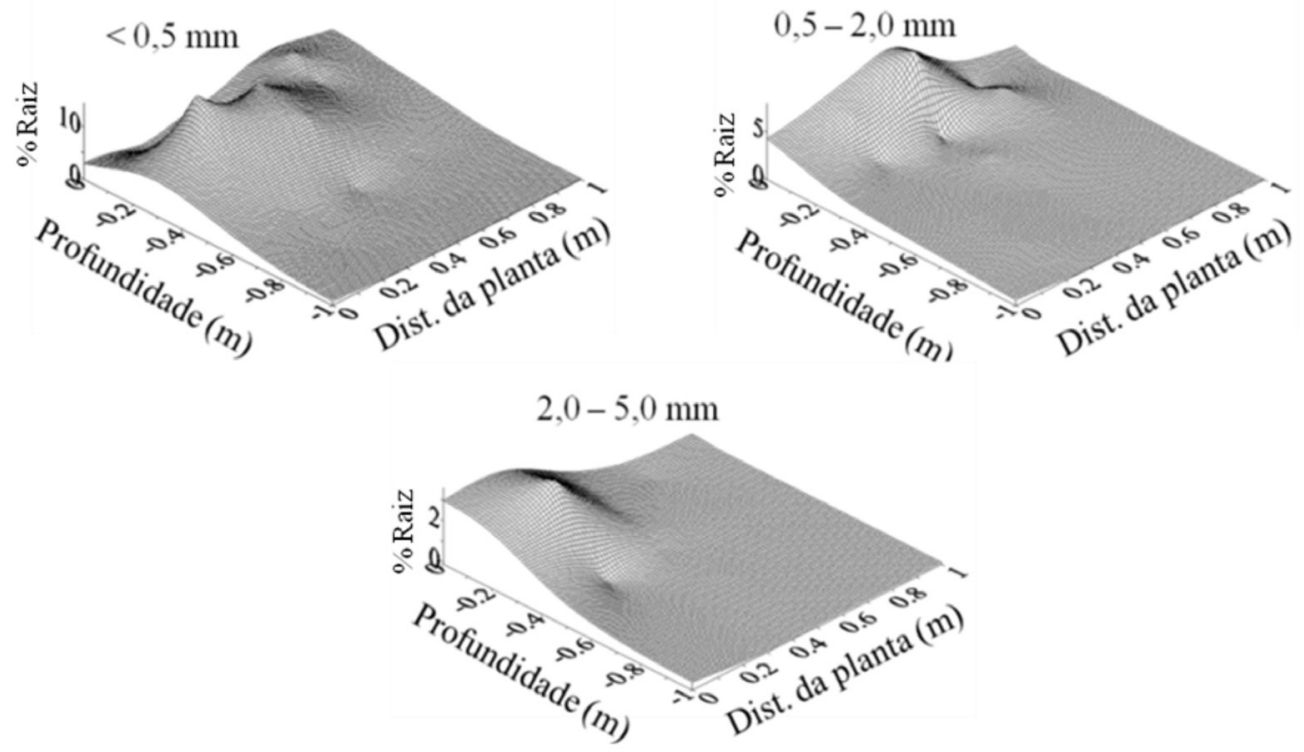

FIGURA 6 - Percentagens de comprimento de raízes de diferentes diâmetros relativo ao comprimento total de raízes de bananeira 'Prata-Anã' sob irrigação por aspersão convencional, tendo a planta na posição zero.

\section{CONCLUSÕES}

1-A distribuição radicular no perfil do solo difere nos sistemas de irrigação por gotejamento, por microaspersão e aspersão convencional.

2-A bananeira apresenta maior predominância do sistema radicular próximo à superfície do solo, com $80 \%$ deste a $0,61 \mathrm{~m}, 0,51 \mathrm{~m}$ e $0,61 \mathrm{~m}$, para os sistemas de irrigação por gotejamento, microaspersão e aspersão convencional, respectivamente.

3-A distância efetiva é de $0,63 \mathrm{~m}, 0,66 \mathrm{~m}$ e 0,79 m do pseudocaule da planta, para os sistemas de irrigação por gotejamento, microaspersão e aspersão convencional, respectivamente.

4-Predominam as raízes de diâmetro inferior a $2 \mathrm{~mm}$.

5-As raízes de maior diâmetro tendem a se concentrar próximo ao pseudocaule da planta e em profundidades inferiores a $0,40 \mathrm{~m}$.

\section{REFERÊNCIAS}

BASSOI, L. H.; SILVA, J. A. M.; SILVA, E. E. G.; RAMOS, C. M. C.; SEDIYAMA, G. C. Guidelines for irrigation scheduling of banana crop in São Francisco Valley, Brazil: I root distribution and activity. Revista Brasileira de Fruticultura, Jaboticabal, v. 26, n. 3, p. 459-463, 2004.

BOHM, W. Methods of studing root systems. New York: Springer-Verlag, 1979. 190 p.

BORGES, A. L.; SOUZA, L. S.; PEIXOTO, C. A. B.; SANTOS JUNIOR, J. L. C. Distribuição do sistema radicular da bananeira 'Prata-Anã' em duas frequências de fertirrigação com uréia. Revista Brasileira de Fruticultura, Jaboticabal, v. 30, n. 1, p. 259-262, 2008.

CAMPOS, R. P.; VALENTE, J. P.; PEREIRA, W. E. Conservação pós-colheita de banana cv. nanicão climatizada e comercializada em Cuiabá - MT, e região. Revista Brasileira de Fruticultura, Jaboticabal, v. 25, n. 1, p. 172-174, 2003.

CARR, M. K. V. The water relations and irrigation requirements of banana (MUSA SPP.). Experimental Agriculture, Cambridge, v. 45, n. 3, p. 333-371, 2009.

COELHO, E. F.; OLIVEIRA, F. C.; ARAÚJO, E. C. E.; VASCONCELOS, L. F. L. Distribuição de raízes de laranja "Pêra" sob sequeiro e irrigação por microaspersão em solo arenoso. Pesquisa Agropecuária Brasileira, Brasília, v. 37, n. 5, p. 603-611, 2002. 
COELHO, E. F.; SIMÕES, W. L.; CARVALHO, J. E. B.; COELHO FILHO, M. A. Distribuição de raízes e extração de água do solo em fruteiras tropicais. Cruz das Almas: EMBRAPA Mandioca e Fruticultura Tropical, 2008. 80 p.

COELHO, E.F.; SANTOS, M.R.; COELHO FILHO, M.A. Distribuição de raízes de mamoeiro sob diferentes sistemas de irrigação localizada em Latossolo de Tabuleiros Costeiros. Revista Brasileira de Fruticultura, Jaboticabal, v.27, n.1, p.175-178, 2005.

DONATO, S. L. R.; LÉDO, A. A.; PEREIRA, M. C. T.; COELHO, E. F. C.; COTRIM, C. E.; COELHO FILHO, M. A. Estado nutricional de bananeiras tipo Prata sob diferentes sistemas de irrigação. Pesquisa Agropecuária Brasileira, Brasília, v. 45, n. 9, p. 980-988, 2010.

DOORENBOS, J.; KASSAM, A. H. Efeitos da água no rendimento das culturas. Campina Grande: UFPB, 1994. 212 p. (Estudos FAO: Irrigação e Drenagem, 33).

EMPRESA BRASILEIRA DE PESQUISA AGROPECUÁRIA. Centro Nacional de Pesquisa de Solos. Sistema brasileiro de classificação de solos. 2. ed. Rio de Janeiro, 2006. 306 p.

FOOD AND AGRICULTURA ORGANIZATION OF THE UNITED NATIONS. FAOSTAT 2010. Disponível em: <http://faostat.fao.org/site/339/default.aspx $>$. Acesso em: 19 out. 2010.

INSTITUTO BRASILEIRO DE GEOGRAFIA E ESTATÍSTICA. Levantamento Sistemático da Produção Agrícola (LSPA). Disponivel em: $<\underline{\text { http: } / /}$ www.sidra.ibge.gov.br/bda/prevsaf/default.asp $>$. Acesso em: 19 out. 2010.

KANBER, R.; KÖKSAL, H.; ÖNDER, S.; EYLEN, M. Effects of different irrigation methods on yield, evapotranspiration and root development of young orange trees. Turkish Journal of Agriculture and Forestry, Ankara, v. 20, n. 2, p. 163-172, 1996.

LACERDA FILHO, R.; SILVA, A. V. C; MENDONÇA, V.; TAVARES, J. C. Densidade do sistema radicular da bananeira 'Pacovan' sob irrigação por aspersão. Revista Brasileira de Fruticultura, Jabo $\neg$ ticabal, v. 26, n. 3, p. 538-539, 2004.

LECOMPTE, F.; PAGES', L.; OZIER-LAFONTAINE, H. Patterns of variability in the diameter of lateral roots in the banana root system the banana root system. New Phytologist, Cambridge, v. 167, n. 3, p. 841-850, 2005.

LEHMANN, J. Subsoil root activity in tree-based cropping systems. Plant and Soil, The Hague, v. 255, n. 1, p. 319-331, 2003.
LYNCH, J. P.; BROWN, K. M. Topsoil foraging: an architectural adaptation to low phosphorus availability. Plant and Soil, The Hague, v. 237, n. 2, p. 225-237, 2001

NEILSEN, G.H.; PARCHOMCHUK, P.; NEILSEN, D.; ZEBARTH, B.J. Drip-fertigation of apple trees affects root distribution and development of K deficiency. Canadian Journal of Plant Science, Ottawa, v. 80, n. 2, p. 353-361, 2000.

OLIVEIRA, F. T. de. Crescimento do sistema radicular da Opuntia fícus-indica (L.) Mill (palma forrageira) em função de arranjos populacionais e adubação fosfatada. 2008. 76f. Dissertação (PósGraduação em Zootecnia - Sistemas Agrossilvipastoris no Semi-árido) - Centro de Saúde e Tecnologia Rural, Universidade Federal de Campina Grande, Campina Grande, 2008.

RAMOS, A.; FOLEGATTI, M. V.; BOVI, M. L. A.; DIOTTO, A. V. Distribuição espacial do sistema radicular da pupunheira em função de lâminas de irrigação. Irriga, Botucatu, v. 14, n. 4, p. 431-440, 2009.

RODRIGUES, M. G. V.; DIAS, M. S. C.; RUGGUERO, C. LICHTEMBERG, L. A. Planejamento implantação e manejo do bananal. Informe Agropecuário, Belo Horizonte, v. 29, n. 245, p. 14- 24, 2008.

RUIZ-SANCHEZ, M. C.; PLANA, V.; ORTUÑO, M. F.; TAPIA, L. M.; ABRISQUETA, J. M. Spatial root distribu $\neg$ tion of apricot trees in different soil tillage practices. Plant and Soil, The Hague, v. 272, n. 1/2, p. 211-221, 2005.

SANTOS, M. R.; COELHO, E. F.; SILVA, A. J. P. da; PINHO, R.E. da C. de ; SANT'ANA, J. A. V.; Coelho Filho, M. A. Distribuição do sistema radicular da bananeira sob diferentes configurações do sistema de irrigação por aspersão. In: REUNIÃO INTERNACIONAL DA ASSOCIAÇÃ̃O PARA A COOPERAÇÃO NAS PESQUISAS SOBRE BANANA NO CARIBE E AMERICA TROPICAL, 17, 2006, Joinville. Anais... Joinville: ACORBAT, 2006. v.1. p. 413-413.

SELLE, G. L.; VUADEN, E.; MURARI, A. B.; HACK, C.; FARIAS, J. A.; THOMAS, R. Biomassa radicular, densidade do solo e análise química do solo de um povoamento de Pinus sp. Ambiência, Guarapuava, v.6, n.1, p.61-74, 2010.

VIEIRA, D. B.; GENOVEZ, A. M.; GOMES, E. M. Determinação da profundidade efetiva do sistema radicular do milho (Zea mays L.) irrigado. In: CONGRESSO NACIONAL DE IRRIGAÇÃO E DRENAGEM, 11., 1996, Campinas. Anais... Campinas: ABID, 1996. p. 95-106. 